\title{
Fábricas textiles en la Isla de León, a fines del setecientos
}

\author{
JUAN TORREJON CHAVES
}

\section{INTRODUCCION}

La Isla de León conoció en el transcurso del siglo XVIII un desarrollo fulgurante, pasando de ser un paraje escasamente ocupado, de hábitat disperso y un predominio absoluto de las actividades agrarias, a convertirse en una villa muy poblada, dedicada preferentemente a la industria y a los servicios. Perteneciente el territorio al Mayorazgo Ducal de Arcos, era cedido en anfiteusis a sencillos colonos y a emprendedoras familias gaditanas, quienes levantaron aquí sus modestas y medianas explotaciones agrarias, y sus fincas de recreo. En los inicios de la centuria decimoséptima solamente cabía suponer para la Isla un porvenir insignificante, supeditado a los intereses de la más activa ciudad española del momento. Pero la intervención determinante del poder central, llegó a configurarla como uno de los núcleos más activos y principales de la España borbónica, destinando el absolutismo ilustrado inversiones tan frecuentes como elevadas; sobre todo a partir de Carlos III, su más claro favorecedor. Nada más hay que acudir a la literatura de viajes de la época para detectar las impresiones tan opuestas que despertó el lugar, según el momento del tránsito o de la estancia: mientras el dominico francés Labat -quien lo conoció en 1706- recibió una sensación tan pobre que ni siquiera se detuvo, los viajeros de finales de la centuria se deshicieron en elogios, como fue el caso de Antonio Ponz, el afamado Secretario de la Real Academia de San Fernando, cuando lo visitó en 1791.

Ya con Felipe V comenzó a apreciarse la importancia que para los programas de revitalización poseía este enclave de los Ponce de León. El propio monarca estuvo en la Isla en la primavera de 1729 , lo que trajo como consecuencia su conversión en tierra de realengo. Anterior- 
mente, y por iniciativa del Intendente General de la Marina y a la vez presidente de la Casa de la Contratación, José Patiño, comenzó el proceso constructivo del Real Arsenal de La Carraca: el elemento técnicoindustrial del Departamento Marítimo de Cádiz, destinado a la construcción, carena, reparación y aprovisionamiento de los bajeles de guerra. Su ubicación en el islote fangoso del cual tomó el nombre, significó desde sus orígenes un factor determinante en el desarrollo económico de la Isla de León, provocando en 1769 el traslado de los Cuerpos de Marina desde la ciudad de Cádiz; acción ésta de efectos determinantes para la potenciación de la villa, que desde 1766 gozaba de un Cabildo municipal autónomo. Por lo ambicioso del empeño, el volumen de lo trabajado, el monto de las inversiones públicas realizadas, la diversidad de las tareas, la introducción de nuevas tecnologías y modos de producción más modernos, las actividades de esta auténtica ciudad industrial no tuvieron parangón con cualesquiera otras del sector secundario aquí asentadas. Pero éstas existieron, y el presente estudio se acerca a las modalidades de carácter textil, ocurridas a finales de la centuria.

Sobre ellas ya advirtió el siglo próximo pasado Joaquín Cristelly en su libro Ligeros apuntes históricos y colección de citas, documentos y datos estadísticos de la ciudad de San Fernando, desde los tiempos más remotos hasta el año 1823, coleccionados por... (1), en el capítulo dedicado a los "Edificios más notables de la ciudad y de sus alrededores", reproduciendo dos documentos: en primer lugar, uno relativo a los géneros elaborados en las fábricas de Cetina, desde el 1 de mayo de 1790 al 31 de mayo de 1791, que está antecedido por un breve comentario; y el segundo, fechado el documento el 8 de junio de 1790 , e incluido a continuación del anterior -sin explicación alguna o aclaración-, que incita a la confusión de considerar que los datos reflejados se relacionan con las primeras fábricas citadas. Pero el análisis de este último documento y su data remiten ineludiblemente a otra instalación industrial ubicada en la misma Isla de León. También existió una tercera, dedicada a la confección de medias y propiedad del comerciante gaditano Juan Bautista Bapallo, que el referido autor no cita.

(1) CRISTELLY, Joaquín: Ligeros apuntes bistóricos y colección de citas, documentos y datos estadísticos de la ciudad de San Fernando, desde los tiempos más remotos basta el año 1823, coleccionados por..., San Fernando, Imprenta y Librería "Española", 1891. Biblioteca "Lobo" del Ayuntamiento de la ciudad de San Fernando. 
Ninguna noticia sobre estas fábricas textiles se dan en dos destacadísimas fuentes secundarias, coetáneas al fenómeno objeto de estudio, donde el tema de la producción textil en la España del momento encontró una amplia cabida. Me refiero a los escritos de Mariano Nipho y Cagigal, y Eugenio Larruga y Boneta. Nipho, con la protección de la Real Junta de Comercio dio a la luz en Madrid, en 1769 el primer tomo del Correo General de España y noticias importantes de Agricultura, Artes, Manufacturas, Comercio, Industria y Ciencias (2), que recogió un "Estado y noticia general de las fábricas de seda, paños, bayetas y sombreros, curtidos, y otros géneros que hay en el Reino, sujetas a la Real Junta General de Comercio y Moneda, y los pueblos donde están establecidos, hasta el año de 1760". De la bahía de Cádiz advierte la existencia en El Puerto de Santa María de una fábrica de mantos de seda, una de tafiletes "como los de berbería", y en Puerto Real fábricas de indianas y lienzos pintados de azul. En el segundo tomo de la obra, publicado en 1770 con igual título que el antecedente, no incluye noticias de las manufacturas gaditanas. En 1771 aparecieron los tomos tercero, cuarto y parte del quinto, con la modificación del título de la obra, que pasaba a denominarse Descripción Natural, Geográfica y Económica de todos los pueblos de España, en continuación del Correo General (3), formada por las noticias que iban remitiendo los corregidores y demás justicias de la península, en cumplimiento de la Orden del Supremo Consejo de Castilla. En la introducción, el autor advierte que ha mudado el título para hacerlo más comprensible y acorde con las preguntas del interrogatorio. El tomo tercero contiene una amplia información, minuciosa y utilisima de la fábrica textil de "La Purísima Concepción" de El Puerto de Santa María -con datos muy interesantes sobre las técnicas de tintadas-, que goza de un reciente estudio en el libro de Juan José Iglesias Rodríguez Una ciudad mercantil en el siglo XVIII: El Puerto de Santa María (4).

(2) NIPHO Y CAGIGAL, Mariano: Correo General de España y noticias importantes de Agricultura, Artes, Manufacturas, Comercio, Industria y Ciencias, etc., que da al público..., Madrid, /s.l./, 1769-1770. Tomo I. Biblioteca Nacional: 5 / 2.641 y R / 60.126. Tomo II. Biblioteca Nacional: Z / 1.574.

(3) NIPHO Y CAGIGAL, Mariano: Descripción Natural, Geográfica y Económica de todos los pueblos de España, en continuación del Correo General, por..., Madrid, /s.l./, 1.771. Tomos III, IV y V. Biblioteca Nacional: $Z / 1.384$.

(4) IGLESIAS RODRIGUEZ, Juan José: Una ciudad Mercantil en el siglo XVII: El Puerto de Santa Maria. Sevilla-El Puerto de Santa María, Servicio de Publicaciones de la Universidad de Sevilla / Fundación Municipal de Cultura de El Puerto de Santa María / Muñoz Moya y Montraveta edit., 1991. 
En las exhaustivas Memorias politicas y económicas sobre los frutos, comercio, fábricas y minas de España, con inclusión de los Reales decretos, órdenes, cédulas, aranceles y ordenanzas expedidas para su gobierno y fomento de Eugenio Larruga, archivero de la Junta de Comercio, no existe información sobre las fábricas gaditanas, ya que la ingente obra -45 tomos en 26 volúmenes- no incluyó la descripción de las andaluzas, ocupándose de las dos Castillas, Extremadura, León y Galicia (5).

El "Extracto de las Respuestas Generales" del Catastro de Ensenada, de 1751, en su punto 33 -"artistas y menestrales, sueldos especificados por días" - la Real Isla presenta una población dedicada a la industria textil de relativa importancia: 47 rastrilladores, 94 hiladores, 49 tejedores de lona, 2 maestros tundidores de lienzos y paños, 10 maestros y 4 oficiales de hacer velas. El "Libro de Comprobaciones" del mismo Catastro, diez años más tarde manifiesta en el mismo punto: 17 rastrilladores, 94 hiladores y 39 fabricantes de lona, 6 de lonilla y 21 maestros para hacer velas (6). Debían pertenecer todos ellos a la Fábrica de Jarcias y Lonas del Real Puente de Zuazo, que surtía a la Armada y que más tarde abandonó el Real carenero para instalarse en el arsenal de La Carraca, una vez que se levantaron las edificaciones al respecto.

Para la descripción de la actividad fabril consecuente, además de los datos aportados por Cristelly en su obra citada más arriba, se ha utilizado la escasísima documentación existente en el Archivo Municipal de San Fernando, en sus legajos n. ${ }^{\circ} 1.530$ y 1.531.

\section{LAS REALES FABRICAS DE CETINA}

Fueron levantadas en la zona suroeste de la isla, cercanas a una elevación de tierra de escasa cota, conocida con el nombre de "Cerro de los Mártires", ya que una religiosa tradición situó en él el martirio de los santos Servando y Germán en la época del emperador Diocle-

(5) LARRUGA Y BONETA, Eugenio: Memorias políticas y económicas sobre los frutos, comercio, fábricas y minas de España, con inclusión de los Reales decretos, órdenes, cédulas, aranceles y ordenanzas expedidos para su gobierno y fomento. Madrid, Imprenta de Benito Cano, 1878-1800. 26 vol. en 45 tomos. Biblioteca Nacional: 1 / 21.523-48 y U / 7.928-72.

(6) Archivo General de Simancas, Dirección General de Rentas, Unica contribución. Respuestas Generales: Sevilla, libros 560-563 y 564. Comprobaciones: Sevilla, 1.612-1.648. 
ciano, que son los patronos tutelares de la ciudad de Cádiz y su Obispado. En las faldas de este montículo se encuentran aún restos de una instalación fabril, que tomó la toponímica denominación de "Cetina", junto a la cual se formó un barrio pequeño que albergó a los operarios del establecimiento y sus familiares; habiendo quedado cartográficamente representado el conjunto en el magnífico plano del "Puerto de Cádiz" que, para el Atlas Marítimo de España, elaboró el brigadier de la Real Armada y Capitán de las Reales Compañías de Guardias Marinas Vicente Tofiño de San Miguel (Plano I). El complejo industrial -bajo la advocación de San José- fue propiedad del comerciante gaditano José de Llano, caballero del Orden de Santiago, siendo sus interventores Francisco Martínez Vallejo, Marqués del Castillo de San Felipe, y Pedro Ignacio del Campo, vecino también de la ciudad de Cádiz y de su Comercio a Indias, y estuvo formado por una fábrica de sombreros, una de tejidos de algodón y una de estampados o pintados. La designación de "Real" no debe inducir a error, considerándola como una empresa organizada por el Estado, de clara progenie colbertista. Se trataba de una actividad de iniciativa y propiedad privada, condicionada en la gestión y privilegiada en su financiación, cuya prestigiosa denominación se realizaba por suponérsele "unos méritos de ejemplaridad en base a los cuales se le concedía una serie de privilegios fiscales y estaba obligada a mantener un adecuado nivel de calidad y producción" (7).

\subsection{La fábrica de sombreros}

En el año 1791 (8) se elaboraron un total de 4.058 sombreros, distribuidos de la siguiente manera:

-1.454 de castor blancos y negros.

- 93 de pelo a la inglesa.

(7) GONZALEZ ENCISO, Agustín: Estado e Industria en el s. XVII: la Fábrica de Guadalajara. Madrid, fundación Universitaria Española, 1980, pp. 155-160.

(8) CRISTELLY, op. cit., pp. 189-191, incluyó en el Documento n. 1 las elaboraciones de las fábricas de Cetina comprendidas entre el 1 de mayo de 1790 y el 31 del mismo mes de 1791. En el Archivo Municipal de San Fernando se guarda un "Extracto de lo elaborado en esta Rl. fábrica de San Josef de Cetina, propia del Sr. Dn. Josef de Llano..., situada en este término de la Rl. Isla de León en el pasado año de 1791", firmado el 6 de mayo de 1792 por Manuel del Castillo. Legajo $\mathbf{n} .{ }^{\circ}$ 1.530, correspondiente a la antigua clasificación del "Estante 1 - Caja 109". Figuran, en una cara del folio los datos relativos a la fábrica de tejidos de algodón y a la fábrica de estampados; por el envés, los correspondientes a la fábrica de sombreros. 
- 478 de $3 / 4$ de castor negro de pelo a la inglesa.

- 426 negros lisos.

-1.404 de $1 / 2$ negros lisos.

- 203 de $1 / 4$ o entrefinos negros.

Los costos de producción se elevaron a un total de 283.324 rs. vón., ocupándose en las tareas 22 varones -20 hombres y 2 muchachos- y 25 mujeres, así organizados:

\begin{tabular}{ll} 
Varones & Mujeres \\
\hline 1 maestro & 1 maestra \\
12 oficiales & 24 entre sacadoras de pelo, \\
3 aprendices & forradoras y descañonadoras \\
3 acabadores u & \\
oficiales de plancha & \\
3 & cardadores
\end{tabular}

Los precios corrientes a que se vendieron por unidad oscilaron:

\begin{tabular}{|c|c|}
\hline Tipo & Rs. vón. \\
\hline Negro liso & $75-70$ \\
\hline Castor blanco y negro & $72-64$ \\
\hline Pelo a la inglesa ......... & $70-60$ \\
\hline $3 / 4$ de castor negro. & $70-60$ \\
\hline $1 / 2$ negro liso & $50-48$ \\
\hline $1 / 4$ o entrefino negro & $20-18$ \\
\hline
\end{tabular}

\subsection{La fábrica de tejidos de algodón}

También en 1791 esta fábrica produjo 68 piezas con 2.238 varas totales:

- 40 de terciopelos de algodón con 1.268 1/4 vs., teñidas y pintadas en las mismas fábricas.

- 8 de cotonías con $3231 / 4$ vs. en blanco y 1 vara de ancho, de diferentes dibujos y clases.

- 7 de fustanes con 262 vs., teñidos de diversos colores.

- 8 de cordoncillo con 262 vs., teñidos de diferentes colores.

- 3 de sargas dobles con 94 vs.

- 2 de sargas doble de pelo con 64 vs.

Su costo alcanzó la cantidad de 36.283 rs. y 8 mrs. vón., y los telares utilizados fueron 8 de los 19 que poseía la fábrica. En esta 
labor se ocuparon 27 varones -17 hombres y 10 muchachos- y 14 mujeres. A saber:

\begin{tabular}{ll} 
Varones & Mujeres \\
\hline 1 maestro hilandero & 8 hilanderas \\
1 maestro tejedor & 3 niñas canilleras \\
8 oficiales tejedores & 3 niñas para desmontar \\
4 muchachos canilleros & \\
1 hombre y 6 muchachos & \\
en los ingenios de & \\
cardar, aspar y torcer & \\
2 cortadores de terciopelo \\
3 hombres en el nuevo \\
método de blanqueo
\end{tabular}

La vara de terciopelo se vendió de 20 a 24 rs. vón.; la de cotonía, de 18 a 40 rs. vón.; la de fustán, de 18 a 20 rs. vón.; la de cordoncillo, de 20 a 22 rs. vón.; la de sarga doble, de 18 a 20 rs. vón.; la de sarga doble de pelo, de 15 a 18 rs. vón.

\subsection{La fâbrica de estampados}

En el mismo año ésta elaboró 104 piezas de estopillas dobles con 3.776 3/4 vs, así distribuidas:

-83 con $2.9323 / 4$ vs. de diferentes colores.

-21 con 844 vs. de pañuelos de guardillas.

El costo de la pintura llegó a los 12.997 rs. vón., dedicándose a la actividad 10 varones -8 hombres y 2 muchachos- y 12 mujeres:

\begin{tabular}{ll} 
Varones & Mujeres \\
\hline 1 maestro tintorero & 12 para matizar \\
8 pintores & \\
2 muchachos para \\
tirar el color
\end{tabular}

Estos pintados se vendieron de $73 / 4$ a 9 rs. vón. la vara y los pañuelos a 80 rs. vón. la docena.

Además de los dedicados a la producción, para el mantenimiento y reparación del conjunto fabril aquí se ocupaban continuamente:

-1 maestro carpintero.

-2 oficiales de carpintería. 
-1 maestro cerrajero.

-1 mozo de cerrajería.

-1 oficial de albañil.

-1 peón de albañilería.

-1 noriante para sacar el agua, con ayuda de 6 bueyes.

-1 cochero con su carruaje y dos caballos, para las conducciones de las manufacturas y la provisión de las fábricas.

Los productos se destinaban para el consumo de la península y del mercado americano, efectuándose su distribución en el almacén que, al respecto, se poseía en la ciudad de Cádiz, donde se despachaba al por mayor y al por menor. Asimismo, la casa de comercio del mismo José Llano embarcaba sus propios productos para América por su cuenta, aunque en cortas cantidades.

\section{LAS INSTALACIONES DEL LUGAR DE "FADRICAS"}

Cartográficamente consta también la existencia, en el término de la Isla de León, de otras fábricas textiles, a finales del siglo XVIII. Al igual que en el caso anterior, se encontraba alejada del núcleo urbano, situada junto al mar en la zona noroeste, cercana al muelle de la Punta de la Cantera, en la zona comprendida entre el Lazareto y los almacenes de pólvora de la Marina. Por la cercana proximidad a Fadricas, donde acudían los barcos surtos en la bahía gaditana para hacer las aguadas, recibió también este nombre. Su posición se explica por la cercanía al muelle de la Punta de la Cantera, por donde sacar los géneros para su más fácil y barato traslado a la ciudad de Cádiz (Plano II). Ocupando las edificaciones de la antigua Casa Blanca, las instalaciones se levantaron a iniciativa de casas de comercio gaditanas -participaron "Valle-hermoso y hermanos" e "Iribarren"-, que hicieron venir hábiles operarios desde Inglaterra y Francia para implantarla. La actividad se centró en hilar y tejer algodón, estampar lienzos -por encima de todo-, y a confeccionar medias de seda; percibiendo los trabajadores sus emolumentos por piezas o varas realizadas, y no por jornada de trabajo, como ocurría en las de Cetina. A ella corresponden los datos aportados por Cristelly en el segundo documento que hizo público (9).

(9) CRISTELLY, op. cit., p. 191, Documento 1.ำ 


\subsection{La fábrica de tejidos}

En el complejo existieron solamente 7 telares con los que 8 operarios realizaron, a lo largo de $1789,2.500$ vs. entre cotonías; alcachados y terciopelos, cuyo valor osciló desde los 6 a los 15 rs. vón.

\subsection{La fábrica de estampados}

La labor de pintado ocupó cuantitativamente el primer lugar de las actividades, variando las mesas de estampar, que oscilaron entre las 15 y las 20 , ocupando entre 200 y 300 operarios. Los datos existentes sobre la manufacturación de todo el año 1789, arrojan un total de 131.000 varas. Considerando la media de los trabajadores, la producción anual por cada uno de ellos se elevó a 524 varas.

La enorme desproporción existente entre lo que se tejía y se estampaba -una diferencia de 128.500 vs.-, obliga a deducir que se recibían de fuera gran cantidad de piezas de tejidos, que aquí eran pintadas. Como la parte más considerable de las exportaciones españolas de tejidos a América estaba formada por "indianas", que en 1792 alcanzaron los 2,3 millones de vs., si referimos una cantidad semejante a 1789 , encontramos que esta fábrica gaditana aportaba el 5,7 por 100 del volumen total de la exportación nacional de lienzos pintados a América.

\subsection{La fábrica de medias de seda}

Los datos sobre la confección de medias de seda se limitan a sólo tres meses de 1789 -enero, febrero y noviembre-, desconociéndose el número de los trabajadores que intervinieron en la elaboración, así como los precios de los productos y de los salarios percibidos:

\section{ENERO:}

-2.964 pares de mujer.

- 219 pares de hombre.

- 187 pares de niño.

\section{FEBRERO:}

-3.445 pares de mujer.

-1.119 pares de hombre.

- 94 pares de niño. 
NOVIEMBRE:

-1.117 pares de mujer.

- 198 pares de hombre.

- 29 pares de niño.

Excepcionalmente, también en este último mes se elaboraron 3 pares de guantes.

\section{LA FABRICA DE MEDIAS DE SEDA DE JOSE BAPALLO}

La escasez de información al respecto no permite precisar el lugar que ocupó en la Real Isla de León, ni el número de sus telares y tejedores (10). A pleno rendimiento, la producción anual en 1790 se cifró en unas 3.000 docenas de medias surtidas de todas clases "a la mayor perfección".

La escasez de las ventas hicieron que sólo se despacharan desde la Isla a Cádiz para su expedición a América, entre los meses de abril hasta diciembre de tal año, 944 docenas y 9 pares, así desglosados:

- 751 docenas y 7 pares de mujer.

- 41 docenas y 2 pares de hombre.

-152 docenas de niño.

(10) Archivo Municipal de San Fernando, Legajo 1.531: "Nota que he sacado de mi borrador diario de las medias... Cádiz y 19 de julio de 1791. Por mi padre Dn. Juan $\mathrm{B}^{\mathrm{a}}$. Bapallo, su hijo Josef." Unas notas añadidas por otra grafia al pie del documento advierten que, el año anterior, se envió la relación de lo producido, computando el número de los telares y operarios y los precios corrientes. Se solicitaba si los género se remitían a América o se despachaban en España. 


\section{REALES FABRICAS DE CETINA Sombreros}

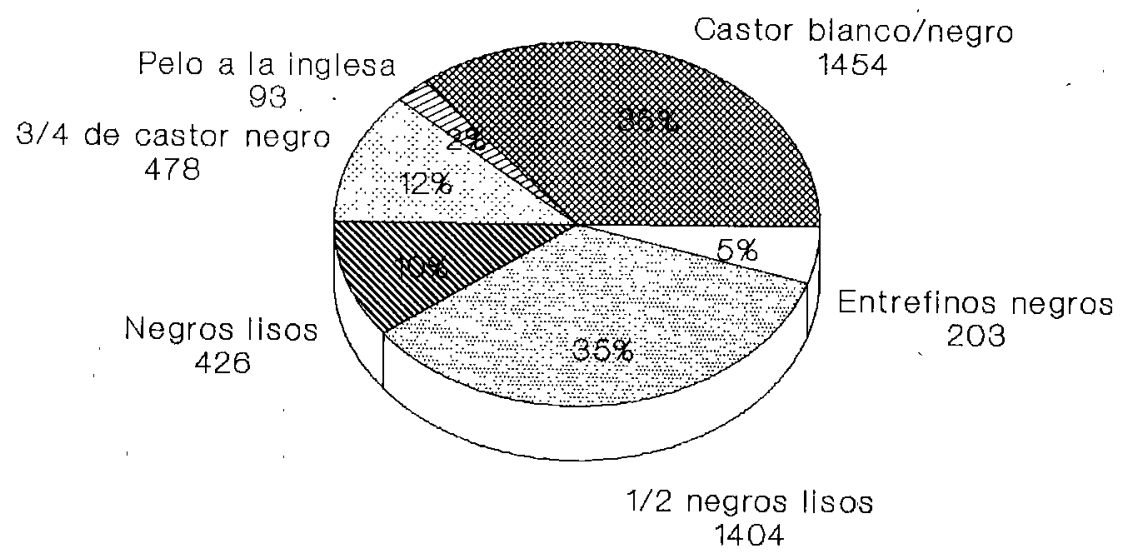

Calidades de Fabricaclón

\section{REALES FABRICAS DE CETINA Sombreros}

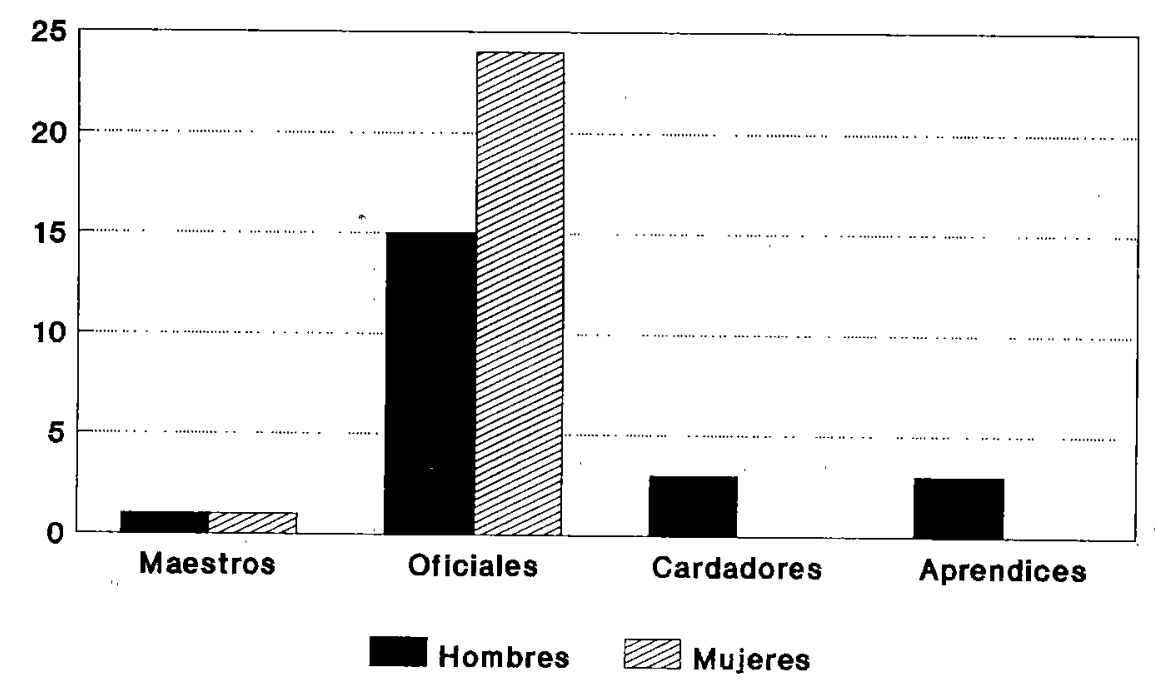

Categorla profeslonal/sexo 


\section{REALES FABRICAS DE CETINA Sombreros}

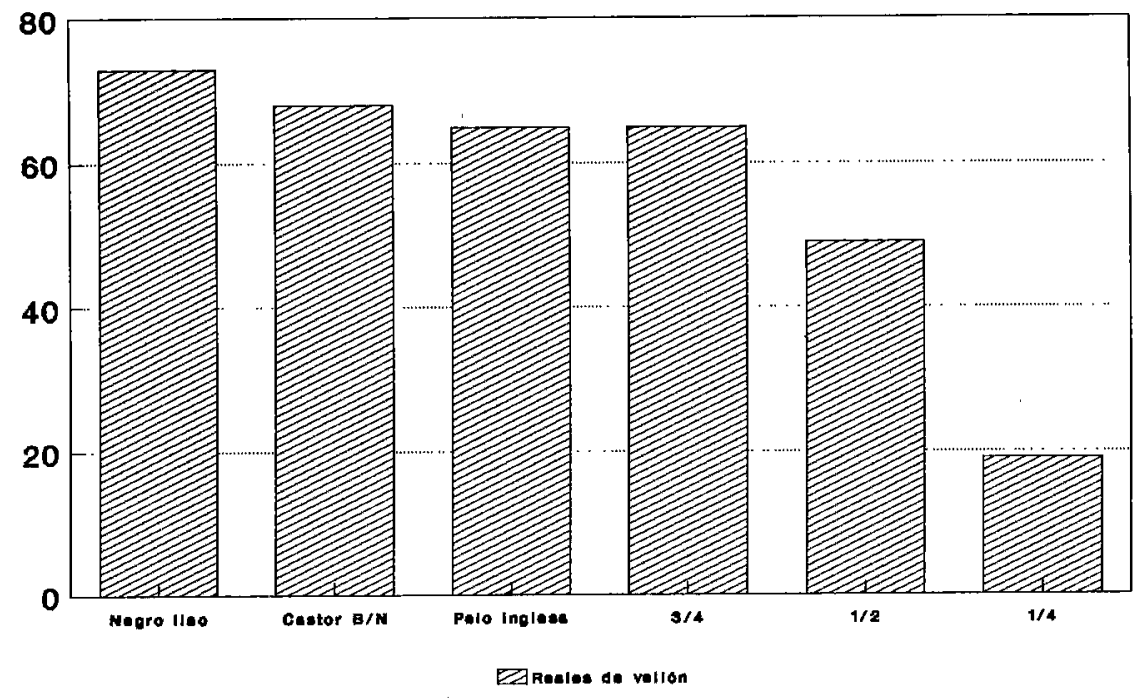

Preclos por unldad

\section{REALES FABRICAS DE CETINA Tejidos de algodón}

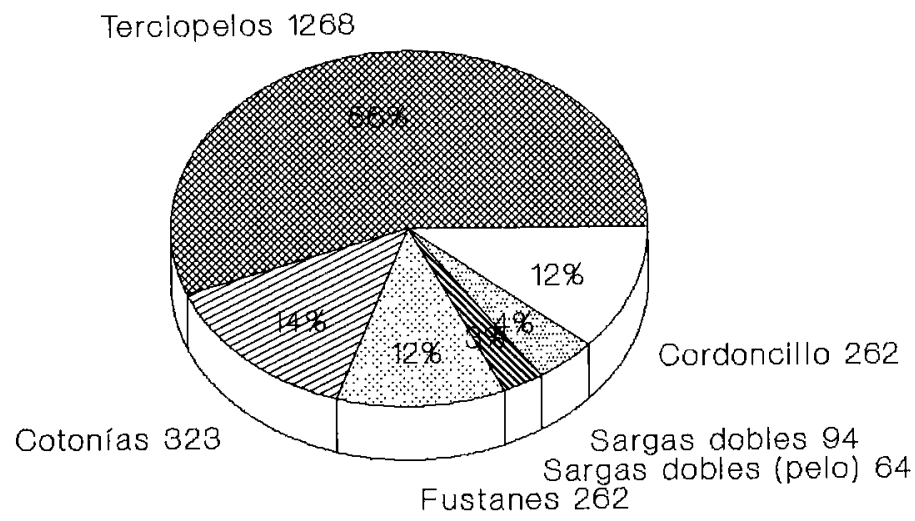

Galldades de fabricaclón (en vs. cast.) 


\section{REALES FABRICAS DE CETINA Tejidos de algodón}

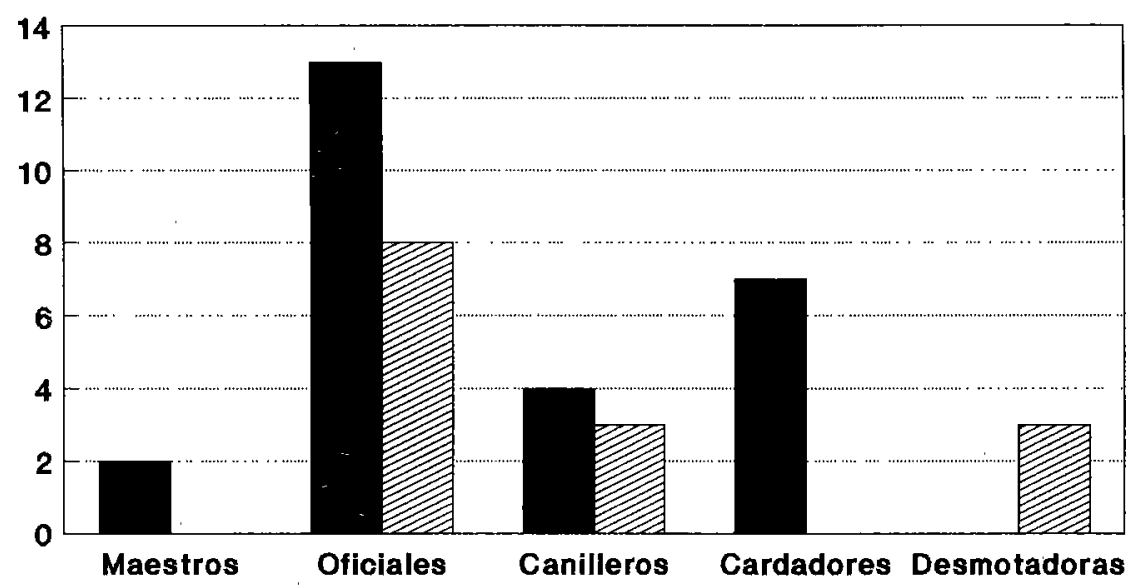

\footnotetext{
Categorla profeslonal/sexo
}

\section{REALES FABRICAS DE CETINA Tejidos de algodón}

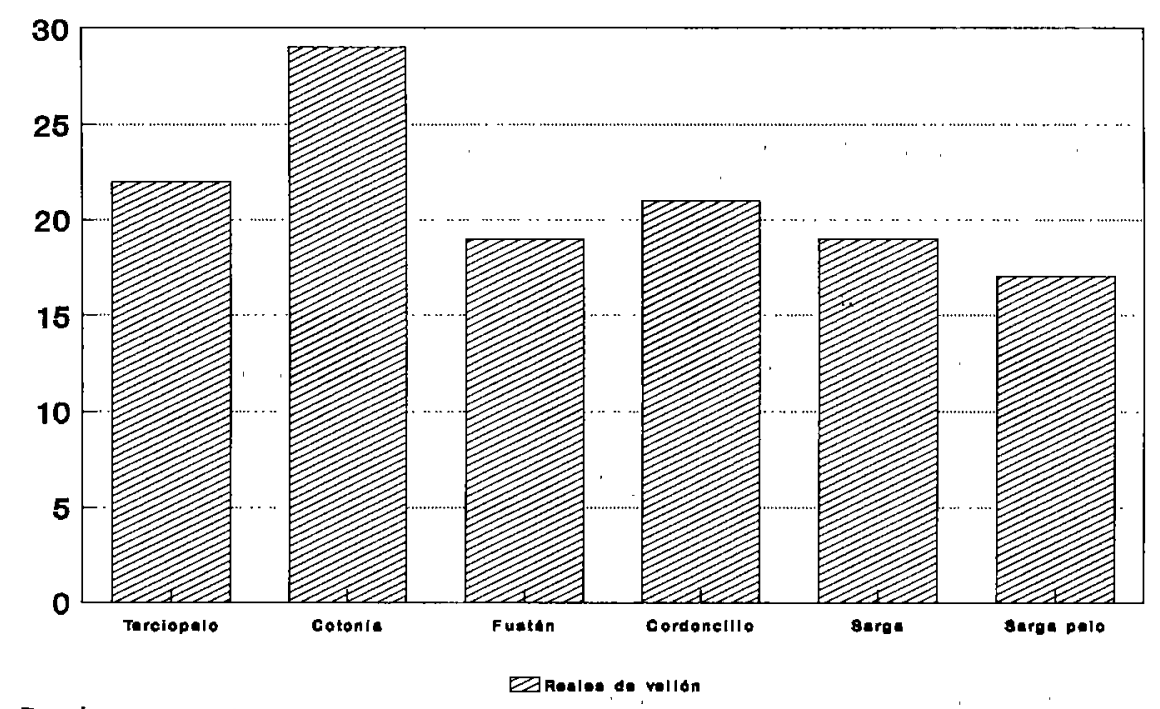

Preclos por vara 


\section{REALES FABRICAS DE CETINA \\ Estampados}

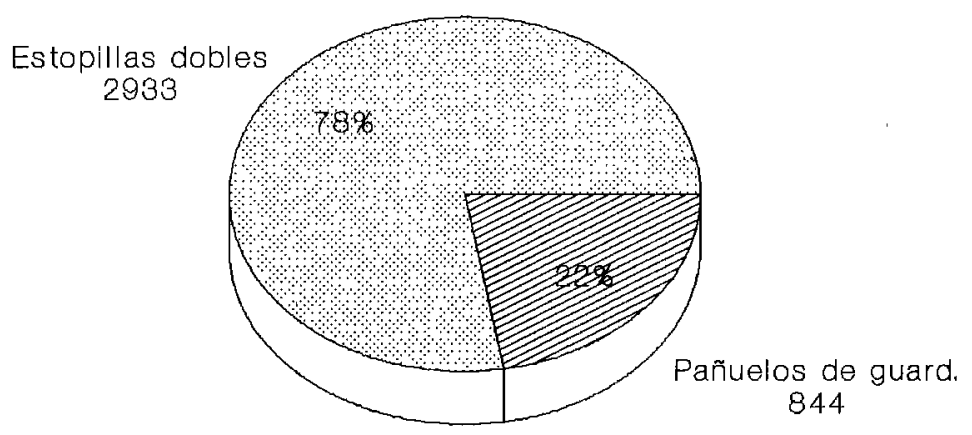

Calldades de fabricaclón (en vs. cast.)

\section{REALES FABRICAS DE CETINA}

Estampados

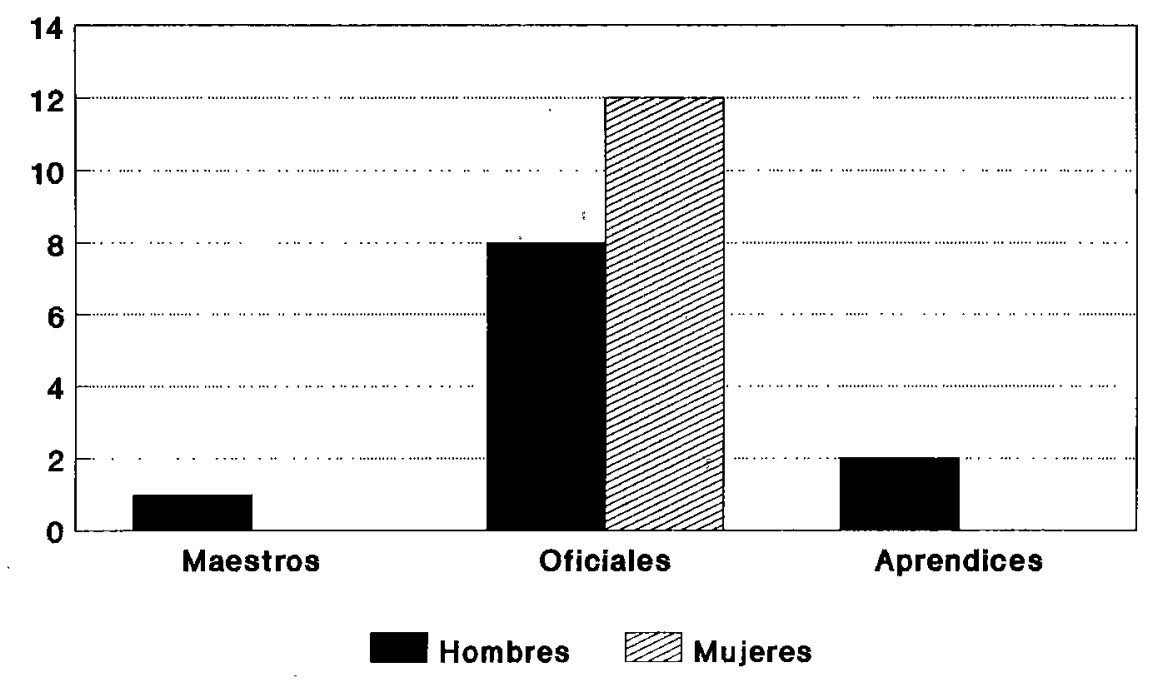

Categorla profeslonal/sexo 


\section{INSTALACIONES DE FADRICAS Medias de sedas}

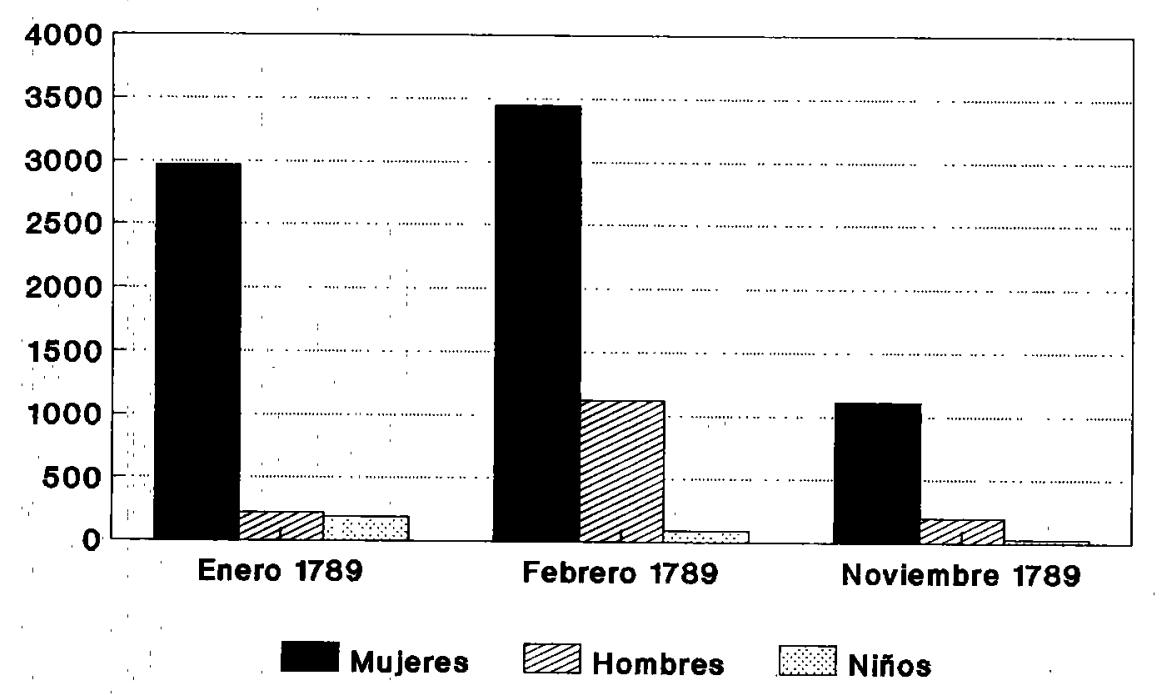

Número dé pares

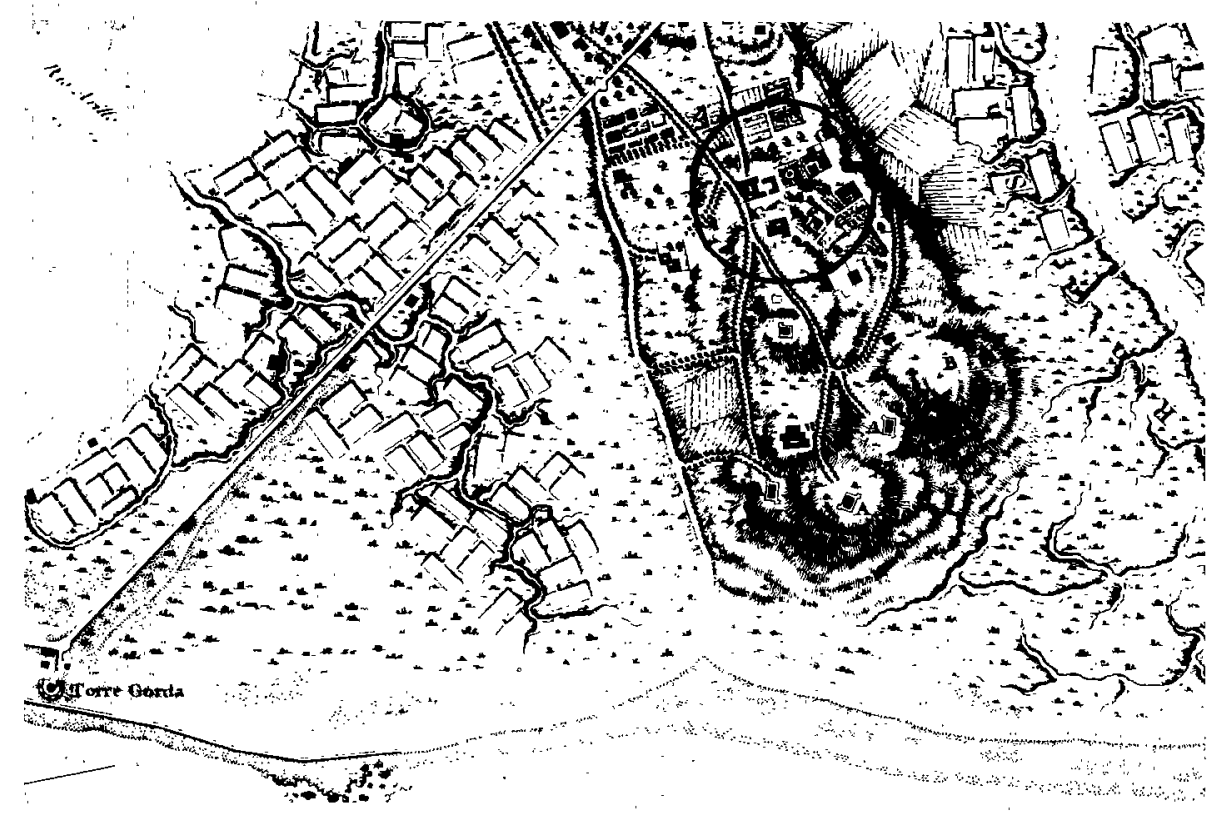

PLANO I. "Puerto de Cádiz" (detalle del territorio SO. de la Isla dé León). Levantado por Vicente Tofiño de San Miguel en 1789. Señaladas con la letra C y, dentro del círculo, las Reales Fábricas de Cetina. 


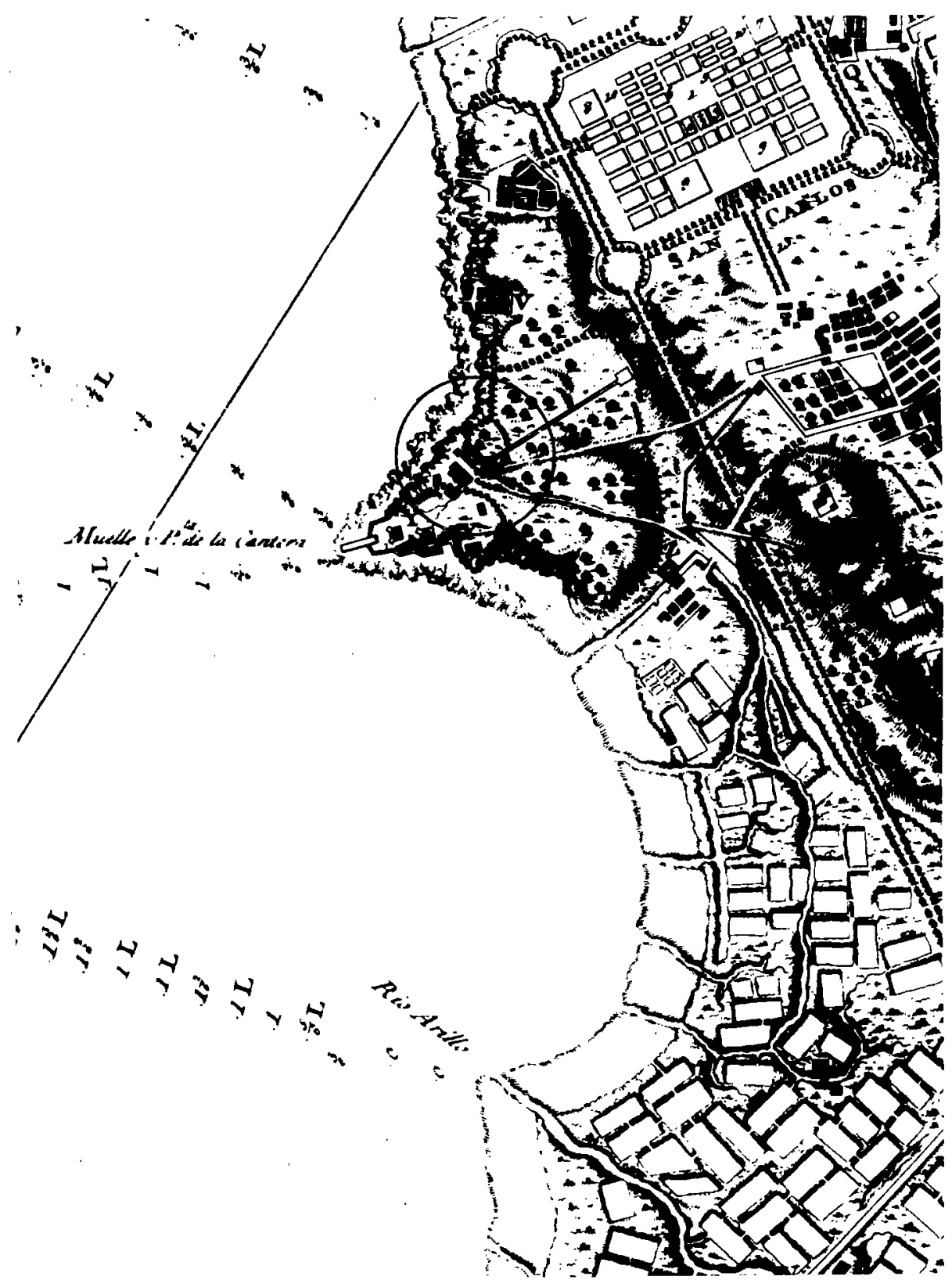

PLANO II. Del mismo plano, detalle de los terrenos de la zona NO. Dentro del círculo, y con la letra X, la Casa Blanca y Fábrica de pintados. 


\section{$*$ \\ REAL CEDULA \\ D E S. M. \\ $\Upsilon$ SEñORES DEL CONSEJO,}

POR LA QUAL SE PERMITE A LOS Fabricantes de Lanas y Seda del Reyno puedan á imitacion de los Estrangeros hacer en sus texidos y manu. facturas las variaciones que consideren precisas en Peyne, Telar y Torno, con tal que á estos texidos se les ponga un sello que los distinga de los arreglados á Orde. nanzas, observándose las demas prevenciones que se expresan para seguridad del comprador.

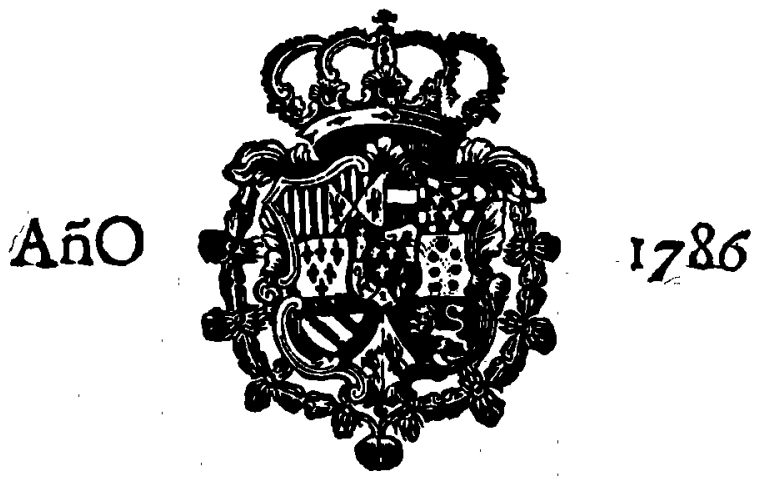

EN CADIZ

En la Imprenta de Don Pedro Gomez de Requèna

Impresór mayor por S. M.; Plazuela

de las Tablas. 


\section{蛋 \\ REAL CEDULA \\ $D E S U$ MAGESTAD}

DE 12 DE DICIEMBRE DE 1784 ,

DECLARANDO POR PUNTO

general estar comprehendidas en el goce de franquicias del Real Decreto de diez $y$ ocho de Junio de mil setecientos cinquenta y seis, y sin sujecion à opresiones gremiales, todas las Fábricas de Medias de Seda fina, Filadís, y Algodon establecidas, y que se establezcan enestos Reynos:

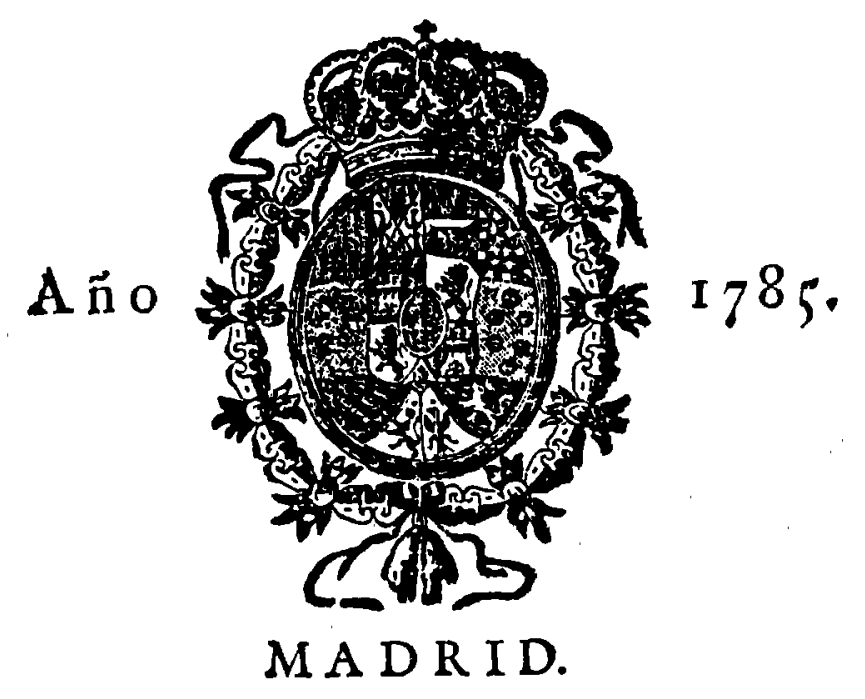

Por Antunio Fernandez. 